\title{
Research on the Integration of Multiple Intelligence Theory and Preschool Children Music Education
}

\author{
Quanlong Qiao \\ Xi'an University, Shaanxi, Xi'an, 710065
}

Keywords: integration; multiple intelligence theory; preschool children; music education

\begin{abstract}
The theory of multiple intelligences confirms that music is a form of human intelligence. It has a profound impact on people's reexamination of music in the overall wisdom of people's construction, development and education methods. It also provides a new perspective and theory for the development of music education for preschool children in China. Based on the theory of multiple intelligences, this paper elaborates the teaching practice of the integration of multiple intelligence theory with preschool children's music education, the multi-intelligence penetration of preschool children's music activities, and the multi-intelligence development of preschool children's music teaching model.
\end{abstract}

\section{Introduction}

The Theory of Multiple Intelligences was developed by Howard Gardner, a famous contemporary psychologist and educationist of Harvard University in the United States, after years of research on psychology, education, and art education, and through observations and analysis of a large number of scientific data and practical cases. of. He believes that humans are born with eight types of intelligence: language intelligence; mathematical logic intelligence; music intelligence; visual space intelligence; To some extent, the eight kinds of intelligence are independent and equal to each other, and each person's intelligence is pluralistic. Everyone has their own superior intelligence and inferior intelligence. The research of multiple intelligence theory provides scientific basis for us to re-understand and excavate the intelligence of students. It has a profound impact on the education concept of the global education community, as well as teaching evaluation concepts, teaching methods and teaching behavior of teachers. At home, the theory of multiple intelligences is one of the important reference theories for the new curriculum reforms that China is implementing, and it also has profound implications for quality education that is currently being implemented in China [1].

The preschool education stage is the initial stage for children to receive formal education. It is the foundation of basic education and the cradle for quality education. It is also the critical period for the comprehensive development of infant intelligence. It is clearly stated in the outline of kindergarten development that kindergarten education should be based on the characteristics of infants' physical and mental development. Music education as part of quality education is indispensable in the overall development of man. The theory of multiple intelligences confirms that music is a form of human intelligence. It has a profound impact on people's reconsideration of music in the overall wisdom construction, development, and educational methods of people. It also provides a new perspective and theory for music education for preschool children in China. Reference, that is, children's music learning is popular learning not for cultivating performers and musicians but for cultivating people's intelligence and basic qualities. In general, children's psychological development has increased with age in most areas. However, the ability of young children in some art fields can reach alarming levels. It is worth noting that after the early childhood, the development of the art shows an inverse U curve, and the plasticity of cognitive representational ability in the nervous system is reduced. Therefore, it can be seen that the development of children's artistic ability has a critical period. Music education plays an important role in promoting the development of early childhood. Such as promoting children's brain development; improving children's language skills; promoting the development of children's perception, memory, and 
association; promoting the development of emotions, wills, contacts, and cooperation capabilities, but how can these functions be brought into full play, not only by combining The physiological and psychological characteristics of preschool children also require a theory as a reference. Multiple intelligence theory confirms that music is a form of existence of human intelligence, and that music intelligence is an important component of multiple intelligent contents. Therefore, the development of preschool children's music intelligence plays an important role in the overall development of children. Then, how to integrate the multiple intelligence theory with the current preschool children's music education and how to establish the teaching practice model in the classroom are all worth studying. In view of this, this dissertation uses the relevant theories of multiple intelligences, combined with China's current preschool children's music education, to explore the integration model of multiple intelligence theory and preschool children's music education, and put forward some constructive thinking and research for preschool children's music education [2].

\section{The Necessity of Preschool Children's Music Education Combined with Multiple Intelligence Theory}

After entering the 21st century, China also attaches great importance to the development and excavation of children's comprehensive intelligence, especially the use of art as a part of the five basic education fields for young children, especially the crossover and integration of music education in different fields, and the intelligence of preschool children. The cultivation process has played an important mediating role. As part of quality education, music education plays a very important role in the overall development of mankind, and based on the theory of multiple intelligences, music is also the most difficult manifestation of human beings. Therefore, in the process of preschool education, re-examine the role of music and encourage music to have a lasting positive impact on the overall development of humans. In this regard, Harvard's "Zero Project" is aimed at further educating early children's artistic potential. In fact, children's psychological development in most fields is continuously improved with the growth of age and experience. However, in some art fields, especially music and music, children's musical intelligence is often more sophisticated than that of adult or adolescent students. It can thus be seen that music education is closely related to the development of young children, especially the ability of cognitive intelligence in the nervous system that music intelligence needs to mobilize. In the early childhood period, human plasticity is the strongest, so preschool music education for young children is very important [3].

Music education plays an important role in the overall development of preschool children, such as helping young children to further develop IQ, or helping young children to further improve their language skills. There is a profound and positive influence on preschool children's perception, memory, or association. Therefore, the emphasis on the combination of multiple intelligence theory and the current preschool children's music education will help to further help preschool children form a diverse and comprehensive intelligence system.

\section{The Integration of Multiple Intelligence Theory and Preschool Children's Music Education}

The principles of multiple intelligences and preschool children's music education are first reflected in the principle of difference. The multi-intelligent practice program for children's IQ development is actually focusing on the characteristics of different pre-school children, as well as different teaching methods based on the characteristics of different regional development. Therefore, it can be seen from this point that the intelligence and the tendencies of each preschool child are divided into many types. This is similar to the fact that different young children actually exhibit different personalities. Therefore, under the support of multiple intelligence theory, preschool children's music education should not be stereotyped, let alone a mandatory index assessment, but should focus on preschool children's talent development, and tap the musical talent of different preschool children. From the aspect of preschool children's music art preferences, preschool children are further encouraged to develop interest in music learning. With the support of multiple 
intelligence education theory, every preschool child should have different intelligence combinations, and these different intelligence combinations will develop at different stages of human life, which means that preschool children's music education should not only focus on In teaching tasks, but also should see the development of each individual's intelligence, should not pursue the consistency of goals and forms of teaching, for each preschool child to open up the world's smart way to expand.

The principle of combining the multiple intelligence theory with preschool children's music education is also reflected in the principle of constructivism. In the middle of the 20th century, the influence of Western constructivist philosophy on teaching behavior was extremely profound. Based on traditional cognitive theory, constructivist learning theory has gradually received more attention in the West. Constructivism originated from the famous psychologist Piaget of the Swiss school of Geneva. He believed that children gradually formed their own understanding of the external world in the interaction with the surrounding environment. Therefore, the environment has a profound influence on children's growth. With the support of multiple intelligence theory, preschool children's music education should also focus on the shaping role of the environment, especially the music learning of preschool children, provide a good environment, strengthen children's individual initiative, and strengthen the formation of their cognitive structure. . In particular, pre-school children's education institutions should form a good music learning scene, so that pre-school children have the opportunity to act independently and fully demonstrate their musical intelligence and musical potential. In the process of teaching, pre-school children should be placed in different musical materials. Pre-school children should be encouraged to use hands-on brains to stimulate the intelligence of pre-school children. Musical intelligence itself is a kind of diversified intelligent embodiment [4].

The integration of multiple intelligence theory and preschool children's music education should focus on the principle of subjectivity. In the educational model of multiple intelligence theory, intelligence has not been emphasized. However, for school education, due to the limitations of its actual teaching conditions, the subject and other disciplines will be distinguished. In the process of preschool children's music education, we should not only see the basic language logic ability of preschool children, but also pay attention to the preschool children's own music literacy, especially the cultivation process of preschool children's basic literacy, and it is indispensable for music and other artistic literacy.

\section{Preschool Children's Music Education and Multi-energy Theory Integrated Teaching Practice Model}

Situational teaching is a kind of teaching mode that teachers can stimulate their thinking, imagination and other intelligence factors by stimulating children's learning motivation, interest and other non-intellectual factors, so as to improve the overall vitality of the psychological structure. The situation creation model plays an important role in the development of infant intelligence. The situational model of music is to create a teaching model that uses language, physical objects, music and other means to create a vivid and realistic situation, to stimulate students' emotions, cultivate students' sentiments, cultivate their personality, and improve their independent participation spirit and cooperation spirit. Feel the beauty, appreciate beauty, and create beauty. Since music is the art of sound, it relies on sounds to shape the image. Therefore, in music teaching, we must create an atmosphere that allows students to listen to the environment to inspire, infect, intoxicate, and inspire students. The content of the lyrics in the children's music context teaching reflects a simple situation that can be understood by young children. These situations can also allow children to express their feelings of experience through physical, sensory and emotional expressions. Let students actively participate in teaching activities and experience the lyric mood directly in person. When children's emotional experience resonates with music, children can truly enter the halls of music, understand and perceive the charm of music, and thus realize the aesthetic value of music [5].

Cooperative learning mode cooperation is an important feature of music performance and performance. The cooperative learning mode of early childhood music teaching activities is to provide children with an opportunity for interpersonal communication and cooperation, to meet the 
needs of children's interactions, and to improve children's ability to communicate with others in order to promote the development of children's interpersonal intelligence. The forms of child care cooperation are varied, such as the coordination of chorus parts in the process of children's music teaching, the coordination of movements and formations during dance, the coordination of various parts during percussion, and music Activities such as discussion and exchange or cooperation in collective and personal cooperation during the event.

Interactive inquiry teaching is a model for teachers to guide young children to actively explore learning. In teaching, teachers create a certain teaching situation. Children learn knowledge, skills, emotions, and attitudes by finding problems independently and independently. This kind of teaching model is easy to stimulate children's interest in learning. It is an open teaching process and focuses on cultivating children's creative thinking ability. Infant music teaching process is not simply to impart the ready-made musical knowledge and skills to children, but to guide children to experience music, such as rhythm, pitch, intensity, and speed, through creative imagination and performance in the actual hands-on operation process.

The above teaching modes influence each other and infiltrate each other. The discussion about the teaching mode is not the standardization of the children's music teaching model. They are a process of dynamic opening and continuous generation. In this process, we need to constantly discover, explore and summarize, so as to better teach children music.

\section{Conclusion}

Of course, the integration of pre-school children's music education and multiple intelligence theory is far more than these. The research on the combination of multiple intelligence theory and preschool children's music education needs to cover a wide range of topics, because the multiple intelligence theory involves many problems, and the related disciplines are also numerous. For example, in-depth research on the theoretical basis of preschool children's music education and multi-intelligence integration, the role of other intelligences in multi-intelligence in promoting the development of music intelligence, strategies for the development of multi-intelligence in children's music education at various ages, and children's music activities Teaching evaluation design issues, children's music teacher quality issues, etc., need to be further studied.

\section{References}

[1] Guo Shengjian. "Discussing the Educational Value of Music Education from Multiple Intelligence Structure Theory" [J]. People's Music, 2004.4.25

[2] Xu Zhuoya. "Psychological Adjustment in Collective Music Activities in Kindergartens" [J]. Preschool education research, 2005.4.33

[3] Li Jixi, Fang Yujun. Multiple Intelligence Theory and Kindergarten Education Concept [J]. Pre-school education, 2000.10.18

[4] Huo Li Yan. "Gardner's Theory of Multiple Intelligences and Its Positive Significance to Early Childhood Education Reform in China" [J]. Preschool education research, 2000.10.95

[5] Zhang Chunling. "Multiple intelligence theory and its impact on quality education" [J]. Chinese Journal of Education, 2002.3.107 